\title{
Attitudes of US physician assistants toward persons with HIV/AIDS
}

\author{
Anja Talley, Kyrie Ritzdorf and Richard D. Muma
}

\begin{abstract}
Background: Early in the HIV/AIDS epidemic, a large number of health care workers had negative attitudes toward persons infected with HIV, but a more positive shift has occurred in these attitudes over the past decade. However, recent information about attitudes of physician assistants (PAs) is missing. Methodology: A nationwide randomized sample of 1,500 PAs was surveyed through the US mail. The AIDS Attitudes Scale (AAS) developed by Froman, Owen, and Daisy in 1992 was used for this purpose. The results were analyzed using descriptive, $t$ test, and analysis of variance (ANOVA) statistics. Results: A majority of respondents had high empathy, low avoidance, and positive general attitude scores. Respondents living in the South had the highest avoidance and lowest general attitude scores compared with those living in other regions (ANOVA, $P<.05)$. Conclusion: The results were consistent with similar current studies of health care workers, which demonstrated supportive attitudes towards persons with HIV/AIDS.
\end{abstract}

Deaths due to HIV/AIDS in the United States have declined in the past decade thanks to improved testing, availability of multidrug treatments, and preventive education. In addition, most management now takes place outside the hospital setting, so the number of clinicians managing HIV/AIDS patients has increased dramatically. ${ }^{1}$ Historically, negative attitudes towards persons living with HIV/AIDS have been documented among providers. ${ }^{1}$ The purpose of this study was to evaluate the current attitudes of PAs toward persons with HIV/AIDS, as they are a part of the heath care team caring for such patients and not widely studied in this regard.

Negative attitudes and perceived stigma towards persons living with HIV/AIDS have existed since the disease was recognized in $1981 .^{2-10}$ Trends among studies showed that the majority of negative or non supportive attitudes were due to a lack of experience and education about persons living with HIV/AIDS and their management. ${ }^{2-10}$

In 1989, one-fourth of cardiac surgeons refused to operate on HIV-infected patients, regardless of the cause of infection. A majority would operate on an HIV-infected patient only if the procedure was urgent. ${ }^{9}$ Both the 1989 and a 1999 survey found that cardiac surgeons were more likely to perform surgery on a patient with hepatitis before performing surgery on an HIV-infected patient. ${ }^{9-10}$ Studies in the 1990s claimed that physicians felt that they were not appropriately educated about HIV/AIDS, that a perceived stigma from the public resulted if they managed persons with HIV/AIDS, and that they feared contracting the virus. ${ }^{2-4}$ Lack of education and experience among physicians were leading factors for referral or refusal of management.

In 1992, most physicians surveyed had not yet cared for an HIV-infected patient. ${ }^{3}$ However, during the same time, other physicians felt comfortable with their knowledge of prevention and diagnosis of HIV/AIDS but were not comfortable managing infected patients who came to their practices. ${ }^{4}$ Respondents in both studies felt inadequately trained and thus could not provide adequate management. ${ }^{3-4}$ Weinberger and colleagues reported that $40 \%$ of US physicians referred or refused new HIV/AIDS cases in 1992, even though the American Medical Association (AMA) considered this practice unethical. ${ }^{4}$ For those physicians willing to care for HIV/AIDS patients, $97 \%$ had problems hospitalizing their patients, and $95 \%$ had difficulties getting these patients home health care. ${ }^{3}$

While many health care workers during the 1990s had negative attitudes and remained skeptical about treating persons with HIV/AIDS, providing health care to HIV-infected patients could not be 
avoided. ${ }^{5}$ Sixty percent of US physicians surveyed were concerned with contagion. ${ }^{4}$ Throughout the 1990 s, a majority of physicians felt that they and their staff were protected by universal precautions when working with homosexual or bisexual HIV-infected patients. Regardless of these precautions, however, they did not feel comfortable managing HIV-infected intravenous drug users (IVDU). ${ }^{2-4,11}$

By 1997, health care workers in general thought that HIV-infected patients deserved adequate treatment, but fewer than $50 \%$ wanted to provide that themselves. ${ }^{2}$ Sixteen years after the recognition of HIV, a perceived stigma remained among health care workers. This stigma likely influenced negative attitudes towards person living with HIV/AIDS. ${ }^{7}$

In 2000, physician assistants (PAs) and nurse practitioners (NPs) reported that, when they did refer HIV/AIDS patients, it was because of lack of experience and the availability of experts on HIV/AIDS to treat their patients. Eighty-two percent of these non-physician clinicians would provide health care, while $18 \%$ would refer. They agreed that a stigma existed towards IVDUs who had contracted HIV but did not believe that these patients "deserved" to get HIV/AIDS. PAs and NPs expressed sympathy towards these patients, did not avoid treating them, and were not fearful of contagion. ${ }^{8}$

\section{METHODOLOGY}

Design and research question

This study was a cross-sectional, random sampling of practicing US physician assistants. The research questions were as follows:

- What are the current attitudes of US PAs concerning persons with HIV/AIDS using the AIDS Attitude Scale by Froman and colleagues? ${ }^{4,11,12}$

- What are the differences in avoidance, empathy, and general attitude scores with selected demographic variables?

To answer the second question, the following null hypothesis was developed: No significant difference will occur on avoidance, empathy, and general attitude scores based on selected demographic variables such as gender, age, and geographic location of employment. Respondents completed a survey of 21 Likert-based questions regarding their attitude towards persons with HIV/AIDS. Additionally, respondents were asked for their specialty, state of practice, age, gender, marital status, years of experience, history of caring for HIV/AIDS patients, PA degree level, and ethnicity.

\section{Participants}

The American Academy of Physician Assistants (AAPA) database was queried in the spring of 2008 to obtain a randomized sample of PAs in the United States $(N=1,500)$. A calculation determined that 382 responses were needed, with a $5 \%$ margin of error, at a $95 \%$ confidence level, based on a population size of 65,000 . A $25 \%$ to $30 \%$ response rate was expected. Therefore, 1,500 PAs were surveyed to ensure approximately 382 responses. The Wichita State University Institutional Review Board approved the project.

\section{Measurement}

In 1992, Froman, Owen, and Daily developed an instrument to assess the attitudes of health care workers towards persons living with HIV/AIDS. ${ }^{5}$ Permission was granted to use that survey instrument for this study's purpose. The AIDS Attitudes Scale (AAS) is a self-reported measure of attitude toward persons with AIDS. Since its introduction in 1992, the AAS has been used in more than 30 research studies. ${ }^{12}$ The AAS is a reliable and valid instrument that measures empathy (14 questions) and avoidance (7 questions) of health care workers.,12 Avoidance is described as the fear of contracting the disease, and empathy is described as supportive attitudes towards persons living with HIV/AIDS. ${ }^{5}$ A 5-point Likert scale was used instead of a 6-point scale to eliminate the AAS survey's "disagree a little" and "agree a little" options in exchange for a more standard "neutral" option. Per Froman and colleagues' instructions for scoring the 
AAS, avoidance and empathy subscores were computed by determining mean scores from responses to the Likert-scale questions. ${ }^{5}$ Thus, it was expected that the avoidance and empathy scores would range from 1 (strongly disagree) to 5 (strongly agree). A high avoidance score would indicate strong avoidance or negative attitudes towards persons with HIV/AIDS; a high empathy score would suggest strong empathy or positive attitudes towards persons with HIV/AIDS. The general attitude score was computed by creating a difference score: empathy score minus avoidance score. The total score was expected to range from -5 to +5 . Positive scores were to indicate a supportive attitude, and negative scores were to indicate an intolerant, nontherapeutic attitude.

"Respondents had high empathy and low avoidance scores, which suggested a supportive attitude toward persons with HIV/AIDs."

\begin{tabular}{|c|c|}
\hline \multicolumn{2}{|l|}{ Age } \\
\hline Mean 40.83; SD +/- 10.73; Range 25-72 & - \\
\hline \multicolumn{2}{|l|}{ Experience (years as a PA) } \\
\hline Mean 10.57; SD +/-8.49; & - \\
\hline Specialty (most frequent selections) & Percent \\
\hline Family practice & 26.0 \\
\hline Internal medicine & 7.7 \\
\hline Emergency medicine & 12.2 \\
\hline Cardiology & 2.8 \\
\hline OB/GYN & 4.1 \\
\hline Pediatrics & 1.2 \\
\hline Psychiatry & 2.4 \\
\hline General surgery & 1.2 \\
\hline \multicolumn{2}{|l|}{ States where practicing (frequency $\geq 10$ ) } \\
\hline California & 11.0 \\
\hline Florida & 6.9 \\
\hline Michigan & 4.1 \\
\hline New York & 10.6 \\
\hline North Carolina & 6.1 \\
\hline Pennsylvania & 5.7 \\
\hline Texas & 6.5 \\
\hline Wisconsin & 4.5 \\
\hline \multicolumn{2}{|l|}{ Gender } \\
\hline Male & 32.9 \\
\hline Female & 67.1 \\
\hline \multicolumn{2}{|l|}{ Marital status } \\
\hline Single & 19.5 \\
\hline Married & 72.0 \\
\hline Separated & 0.8 \\
\hline Divorced & 6.1 \\
\hline Widowed & 0.4 \\
\hline \multicolumn{2}{|l|}{ Cared for HIV/AIDS patients } \\
\hline Yes & 82.5 \\
\hline No & 13.8 \\
\hline
\end{tabular}




\begin{tabular}{|l|c|}
\hline Degree & \\
\hline Certificate & 14.2 \\
\hline Bachelor & 37.4 \\
\hline Master & 47.2 \\
\hline Ethnicity & 3.7 \\
\hline African American & 4.1 \\
\hline Hispanic & 85.0 \\
\hline White & 1.2 \\
\hline Asian & 1.2 \\
\hline Native American & 4.5 \\
\hline Other & \\
\hline $\begin{array}{l}\text { Note: Percent columns may not add up to } 100 \% \text { because of rounding and respondent } \\
\text { omissions. }\end{array}$ \\
\hline
\end{tabular}

\section{Data analysis}

Means and standard deviations of respondents' avoidance, empathy, and general attitude scores were calculated. Frequency distributions were used to describe the respondents' demographic characteristics. $T$ tests were performed to determine significant differences in the mean scores of avoidance, empathy, and general attitude in regard to specialty (primary care $=$ family practice, internal medicine, pediatrics; specialty = all others), age (divided into two groups based on midpoint ranges, 2538 years and 39-72 years) gender, marital status (married or single), years of experience (divided into two groups based on midpoint ranges, $0-8$ years, $>8$ years), history of care for HIV/AIDS patients (yes, no), PA degree level (undergraduate or graduate), and ethnicity (minority or nonminority). A one-way analysis of variance (ANOVA) with Bonferroni correction examined differences in avoidance, empathy, and general attitude scores, based on state of practice (recoded into the four United States Census Bureau regions [Northeast, Midwest, South and West]). SPSS V 17.0 was used to analyze the data. The alpha level was set at .05 .

\section{RESULTS}

Descriptive statistics and demographic profile

The number of surveys returned was 246 ( $16 \%$ response rate). Characteristics of respondents can be found in Table 1. The mean avoidance score was $1.79(+/-0.51)$, and the empathy score was $4.55(+/-$ $0.46)$. The mean general attitude score was $2.78(+/-0.82)$ (Table 2$)$.

Table 3 shows avoidance, empathy, and general attitude scores based on demographic variables. Significant differences in avoidance scores occurred between age groups, gender, and marital status. Empathy scores were significantly different for gender. General attitude scores were significantly different for age group, gender, and marital status. A significant difference between the Northeast and South existed for avoidance scores only (Table 4). 


\begin{tabular}{|c|c|c|c|}
\hline & Mean & SD & Range \\
\hline Avoidance & 1.79 & $+/-0.51$ & $1-3.18$ \\
\hline Empathy & 4.55 & $+/-0.46$ & $2.33-5.00$ \\
\hline General attitudes & 2.78 & $+/-0.82$ & $0.26-4.00$ \\
\hline
\end{tabular}

\section{DISCUSSION}

The response rate was disappointing. We expected that because PA faculty and students were collecting these data, the response rate would be larger than required. Because this did not occur, homogeneity of variance was examined for all ratio data. Of the $24 t$ tests conducted, four showed the data were not homogenous. Therefore, all $t$-tests results were analyzed using t-scores in which equal variances were not assumed. This change resulted in the empathy t-score based on ethnicity no longer being significantly different. All other significant differences noted in Table 3 remained.

Overall, the respondents had high empathy and low avoidance scores. The respondents also had a positive general attitude score. These scores suggest a supportive and therapeutic attitude towards persons with HIV/AIDS, which was different from attitudes seen earlier in the epidemic among most health care providers..$^{2-4,6,7}$ One reason for a shift from negative to more positive attitudes is that health care providers have become more knowledgeable and experienced with the management of persons with HIV/AIDS. ${ }^{8}$

\section{The findings in context}

Empathy, avoidance, and general attitude scores were consistent with previous studies using the AAS. The mean avoidance score for this study was 1.79 (based on a 5-point Likert scale), as compared to 2.07 for Martin and Bedimo's study, ${ }^{8} 2.37$ for Gillispie and Davis, ${ }^{13}$ and 2.09 and 2.14 for Froman and colleagues ${ }^{1,5,12}$ (based on a 6-point Likert scale). Respondents had a mean empathy score of 4.55 (based on a 5-point Likert scale) as compared to 5.44 for Martin and Bedimo, ${ }^{8,5} 19$ for Gillispie and Davis, ${ }^{13}$ and 5.27 and 5.08 for Froman and colleagues ${ }^{1,5,12}$ (based on a 6-point Likert scale). The respondents' general attitude score was considered positive (2.78, based on a 5 -point Likert scale) compared to the Gillispie study, which was also considered positive (2.82, based on a 6-point Likert scale). ${ }^{13}$ General attitude scores were not calculated in the studies by Martin and Bedimo ${ }^{7}$ or Froman and colleagues. ${ }^{1,5,12}$

\begin{tabular}{|c|c|c|c|c|c|c|}
\hline \multicolumn{7}{|c|}{ TABLE 3. scores by demographic characteristics ( $\mathrm{n}=237$ ) } \\
\hline & Mean (SD) & $t$ value & Mean (SD) & $t$ value & Mean (SD) & $t$ value \\
\hline & & & & & & \\
\hline Specialty & & & & & & \\
\hline Primary care & & & & & & \\
\hline Specialty & & & & & & \\
\hline Age (y) & & & & & & \\
\hline $25-38$ & & & & & & \\
\hline $39-72$ & & & & & & \\
\hline Gender & & & & & & \\
\hline Male & & & & & & \\
\hline Female & & & & & & \\
\hline Marital Status & & & & & & \\
\hline
\end{tabular}




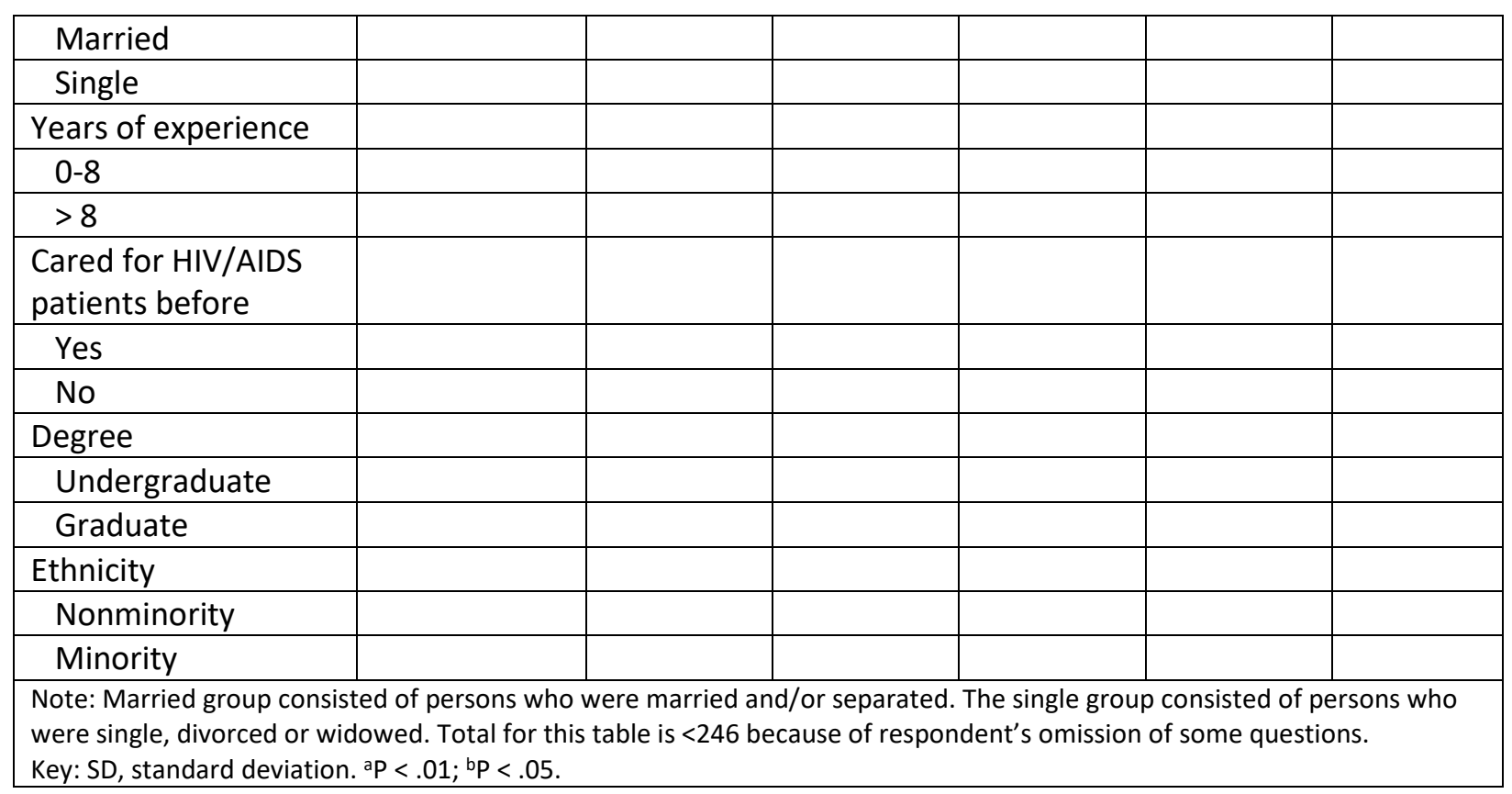

The respondent characteristics were also similar to studies that utilized the AAS. ${ }^{1,5,8,12,13}$ The majority of the respondents were female, white, and married. Significant differences in mean scores of avoidance, empathy, and general attitude occurred between genders, age groups, and bi-marital status. Younger, married, male respondents were less supportive in their attitudes towards persons with HIV/AIDS than those respondents who were older, single, and female.

The mean avoidance score (1.88) was higher in the younger population (25-38 years), consistent with Martin and Bedimo. ${ }^{8}$ The younger population also had a lower mean general attitude score (2.67). According to Chen, age has an effect on empathy in that concern and perception may increase with maturity. ${ }^{14}$ Bennet also stated that empathy evolves with human growth and depends on imagination and open-mindedness. ${ }^{15}$

\begin{tabular}{|c|c|c|c|}
\hline Census region & Avoidance (+/-SD) & Empathy (+/-SD) & General attitudes (+/-SD) \\
\hline Northeast & $1.66(.49), n=51^{a}$ & $4.48(.53), n=51$ & $2.81(.83), n=50$ \\
\hline Midwest & $1.81(.44), n=54$ & $4.54(.46), n=54$ & $2.73(.83), \mathrm{n}=54$ \\
\hline South & $1.91(.49), \mathrm{n}=77^{\mathrm{a}}$ & $4.54(.45), \mathrm{n}=78$ & $2.66(.79), n=76$ \\
\hline West & $1.72(.55), \mathrm{n}=55$ & $4.69(.38), n=53$ & $2.96(.79), n=52$ \\
\hline
\end{tabular}

Female respondents tended to have lower avoidance (1.72), higher empathy (4.61), and a higher general attitude score (2.89) than male respondents. This was in contrast to Martin and Bedimo's study, which found females to be more avoidant. ${ }^{8}$ Many studies in the past several years find women to be more empathetic and less avoidant. Men tend to have significantly lower empathy scores compared to women in the same profession. ${ }^{16-19}$ Hojat and colleagues concluded that women are more receptive to emotions; therefore, they have the tendency to develop stronger and more understanding relationships with their patients. ${ }^{17,18}$ The providers with higher empathy have a better understanding of the patient's feelings and experience; therefore, they have a more positive effect on patient care and outcomes. ${ }^{16}$ 
Married PAs had higher avoidance (1.85), lower empathy (4.54), and lower general attitude (2.70) scores compared to single respondents. Earlier studies referenced did not evaluate marital status in relationship to the three scores. ${ }^{1,5,8,12,13}$ Breault did evaluate marital status and found that married providers were mostly concerned about putting their spouse and/or children at risk if they cared for people with HIV/AIDS. Spouses of these health care workers also stated this concern. ${ }^{20}$

"While it is easy to document inequalities that produce loss of life or health, it is more difficult to determine the causes."

Those living in the South had the highest avoidance and lowest general attitude scores towards persons with HIV/AIDS compared to those living in the Northeast, West, and Midwest. No other studies have reported this. These findings may be related to the long history of discrimination in the southern United States, ${ }^{21,22}$ but further research is warranted in this regard. Discrimination exists in other parts of the United States, and health care has a long history of discrimination towards certain groups as well. ${ }^{22,23}$ Health care disparities can produce loss of life or health among patients with a variety of health problems, and while it is easy to document these inequalities, it is more difficult to determine the causes. ${ }^{21,22}$ Unconscious prejudice may play a role and affect the quality of care given. ${ }^{23-25}$ Dovidio and colleagues state that these negative feelings "are not of hatred or open contempt, which motivate direct harm, but are rather of anxiety and discomfort, which lead to avoidance." 24

\section{Limitations}

This is the most recent study to assess the attitudes of practicing PAs towards persons with HIV/AIDS and the first to use the AAS exclusively with this group. Physician assistants had positive attitudes, similar to other health care providers evaluated. ${ }^{8,12,13}$ This is an encouraging outcome as an emphasis has been placed on health care providers in general, and PAs in particular, to become more knowledgeable and experienced in managing persons with HIV/AIDS.

This survey was limited by a smaller return rate than expected; therefore, generalizations should be regarded with caution. However, when comparing all of the demographics listed in Table 1 with the 2008 AAPA Census (the year this study was conducted), the sample was virtually identical in everything except marital status and care for HIV patients. ${ }^{26}$ These data were not found in the AAPA Census. Furthermore, attention bias could be possible because respondents were aware of their involvement in a research study and might have given more favorable answers than what they really believed. According to Martin and Bedimo, "although it is gratifying to see that these clinicians exhibit high empathy scores, these scores may be partly influenced by the phenomenon of social desirability." Those who did not respond to the survey could also have skewed the data if their attitudes differed from the respondents. Another limitation may be the difference in Likert scales used. This study used a 5-point scale, whereas most other AAS studies used a 6-point scale.

\section{CONCLUSION}

Physician assistants who responded to the survey expressed supportive attitudes towards persons with HIV/AIDS. This finding is consistent with recent data regarding other health professionals. Nevertheless, this outcome may reflect in some way how committed respondents were to the topic, rather than PA attitudes in general, and a longitudinal study of practicing PAs' attitudes toward HIV/AIDS may help to sort this out. 


\section{REFERENCES}

1. Froman RD, Owen SV. Measuring attitudes toward persons with AIDS: the AAS-G as an alternate form of the AAS. Sch Inq Nurs Pract. 2001;15(2):161-174,175-177.

2. Hodgson I. Attitudes towards people with HIV/AIDS: entropy and health care ethics. J Adv Nurs. 1997;26(2):283-288.

3. Abadie R, Hoffman E. Physician practices and attitudes on HIV-related issues: a survey of LSMS primary care physicians. J La State Med Soc. 1992;144(6):283-288.

4. Weinberger $M$, et al. Physicians' attitudes and practices regarding treatment of HIV-infected patients. South Med J. 1992;85(7):683-686.

5. Froman RD, Owen SV, Daisy C. Development of a measure of attitudes toward persons with AIDS. Image J Nurs Sch. 1992;24(2):149-152.

6. Plant ML, Foster J. AIDS-related experience, knowledge, attitudes and beliefs amongst nurses in an area with a high rate of HIV infection. J Adv Nurs. 1993;18(1):80-88.

7. Tabak NT, Ben-Or T, Zur F. Health nurses: attitudes towards treating AIDS patients. Med Law. 1997;16(4):729-742.

8. Martin JE, Bedimo AL. Nurse practitioner, nurse midwife and physician assistant attitudes and care practices related to persons with HIV/AIDS. J Am Acad Nurse Pract. 2000;12(2):35-41.

9. Condit D, Frater RW. Human immunodeficiency virus and the cardiac surgeon: a survey of attitudes. Ann Thorac Surg. 1989;47(2):182-186.

10. Frater RW. As originally published in 1989: human immunodeficiency virus and the cardiac surgeon: a survey of attitudes. Updated in 1999. Ann Thorac Surg. 1999;67(4):1203-1204.

11. Fusilier M, Manning MR, Santini Villar AS, Torres Rodriquez D. AIDS knowledge and attitudes of healthcare workers in Mexico.J Soc Psychol. 1998;138(2):203-210.

12. Froman RD, Owen SV. Further validation of the AIDS Attitude Scale. Res Nurs Health. 1997;20(2):161167.

13. Gillispie LC, Davis BA. Attitudes of nurses caring for HIV/AIDS patients. AIDS Patient Care STDS. 1996;10(5):292-295.

14. Chen D, Lew R, Hershman W, Orlander J. A cross-sectional measurement of medical student empathy. J Gen Intern Med. 2007;22(10):1434-1438.

15. Bennet JA, DeMayo M, Saint Germain M. Caring in the time of AIDS: The importance of empathy. Nurs Admin Q. 1993;17(2):46-60.

16. Hojat M, Fields SK, Gonnella JS. Empathy: an NP/MD comparison. Nurse Pract. 2003;28(4):45-47.

17. Hojat M, Gonnella JS, Mangione S, et al. Empathy in medical students as related to academic performance, clinical competence and gender. Med Educ. 2002;36(6):522-527.

18. Hojat M, Gonnella JS, Nasca TJ, et al. Physician empathy: definition, components, measurement, and relationship to gender and specialty. Am J Psychiatry. 2002;159(9):1563-1569.

19. Fields SK, Hojat M, Gonnella JS, et al. Comparisons of nurses and physicians on an operational measure of empathy. Eval Health Prof. 2004;27(1):80-94.

20. Breault AJ, Polifroni EC. Caring for people with AIDS: nurses' attitudes and feelings. J Adv Nurs. 1992;17(1):21-27.

21. Geiger HJ. Racial and ethnic disparities in diagnosis and treatment: a review of the evidence and a consideration of causes. In: Smedley BD, Stith AY, Nelson AR, eds. Unequal Treatment: Confronting Racial and Ethnic Disparities in Health Care. Washington, DC: The National Academies Press; 2003:417-454.

22. Weisfeld A, Perlman RL. Disparities and discrimination in health care: an introduction. Perspect Biol Med. 2005;48(1 suppl):S1-S9.

23. Geiger HJ, Borchelt G. Racial and ethnic disparities in US health care. Lancet. 2003; 362(9396):1674. 
24. Dovidio JF, Penner LA, Albrecht TL, et al. Disparities and distrust: the implications of psychological processes for understanding racial disparities in health and health care. Soc Sci Med. 2008;67(3):478-486.

25. Baicker KA, Chandra A, Skinner JS. Geographic variation in health care and the problem of measuring racial disparities. Perspect Biol Med. 2005;48(1 suppl):S42-S53.

26. American Academy of Physician Assistants. 2008 AAPA Census. http://www.aapa.org/about-pas/dataand-statistics/aapa-census/2008-data. Accessed November 1, 2010.

27. Hartman JM, Farsen JW Jr, Wallace MS, Neely JG. Tutorials in clinical research: part IV: recognizing and controlling bias. The Laryngoscope. 2002;112(1):23-31. 